\title{
Antimicrobial Resistance Profile of $E$. coli Isolated from Raw Cow Milk and Fresh Fruit Juice in Mekelle, Tigray, Ethiopia
}

\author{
Haftay Abraha Tadesse $(\mathbb{D}$, Netsenet Berhe Gidey, Kidane Workelule, Hagos Hailu (D), \\ Seyfe Gidey, Abrha Bsrat, and Habtamu Taddele
}

College of Veterinary Medicine, Mekelle University, P.O. Box 2084, Mekelle, Ethiopia

Correspondence should be addressed to Haftay Abraha Tadesse; haftay24@gmail.com

Received 22 October 2017; Revised 23 December 2017; Accepted 5 February 2018; Published 19 March 2018

Academic Editor: Ingo Nolte

Copyright (c) 2018 Haftay Abraha Tadesse et al. This is an open access article distributed under the Creative Commons Attribution License, which permits unrestricted use, distribution, and reproduction in any medium, provided the original work is properly cited.

\begin{abstract}
Aim. Foodborne illnesses represent a public health problem in developed and developing countries. They cause great suffering and are transmitted directly or indirectly between animals and humans and circulate in the global environment. E. coli are among them, causing a major public health problem. The aim of this study was therefore to study the antimicrobial resistance profile of $E$. coli from raw cow milk and fruit juice. Materials and Methods. A cross-sectional study was conducted from October 2016 to June 2017 on 258 samples collected from milk shops $(n=86)$, dairy farms $(n=86)$, and fruit juice $(n=86)$ in different subcities of Mekelle. Bacteriological procedures were used for isolation of E. coli in the collected samples and for identification of the antimicrobial resistance profile. Result. The overall mean viable bacterial count and standard deviation of samples from milk shop, fruit juice, and dairy milk were found to be $8.86 \pm 10^{7}, 7.2 \pm 10^{7}$, and $8.65 \pm 10^{7} \mathrm{CFU} / \mathrm{ml}$ and $33.87 \pm 10^{6}, 6.68 \pm 10^{6}$, and $22.0 \pm$ $10^{6}$, respectively. Of the samples tested, 39 from milk shops (45.35\%), 20 from fruit juice (23.26\%), and 24 from dairy farms (27.91\%) were found to be positive for $E$. coli. The isolated E. coli were highly resistant to ampicillin (70\%), sulfamethoxazole-trimethoprim (60\%), clindamycin (80\%), erythromycin (60\%), chloramphenicol (50\%), and kanamycin (50\%) and were found to be susceptible to some antibiotics like gentamicin (100\%), norfloxacin (100\%), tetracycline (60\%), polymyxin B (90\%), and ciprofloxacin (90\%). Conclusion. The current study supports the finding that raw milk and fruit juice can be regarded as critical source of pathogenic E. coli. This supports the need for strict monitoring and the implementation of effective hygienic and biosecurity measures in the whole food chain of these products as well as a prudent use of antimicrobials.
\end{abstract}

\section{Background}

Foodborne illnesses are an important challenge to public health and cause significant economic problem in many countries [1]. The crucial goal of all food safety programs is to prevent food products contaminated by potential pathogens from reaching the consumer. Milk is an excellent medium for bacterial growth, which not only spoils the milk and associated products but also can cause infections in consumers [2]. Because of the specific production, it is not possible to fully avoid contamination of milk with microorganisms; therefore the microbial contamination of milk is an important tool in determining its quality $[3,4]$. Huge numbers of microbes can get access to milk and various milk products including E. coli, which is an indicator of milk and fruit juice contamination, constituting a public health hazard [5]. E. coli infection is a disease that can be transmitted directly or indirectly between animals and humans [6].

It is common in developing countries such as Ethiopia because of the prevailing poor food handling and sanitation practices, inadequate food safety laws, weak regulatory systems, lack of financial resources to invest in safer equipment, and lack of education for food handlers [7]. In countries where foodborne illness were investigated and documented, the relative importance of pathogens like $S$. aureus, Campylobacter, E. coli, and Salmonella species was recorded as a major cause $[1,8]$. These organisms were known to cause acute gastroenteritis and may cause a more serious septicemic disease, usually in the very young, the elderly, or immunocompromised subjects $[9,10]$. 
The ability of these microorganisms to survive under adverse conditions and to grow in the presence of low levels of nutrients and at suboptimal temperatures and $\mathrm{pH}$ values presents a formidable challenge to the agricultural and foodprocessing industries. The continued prominence of raw meats, eggs, dairy products, vegetable sprouts, fresh fruits, and fruit juices as the principal vehicles of human foodborne diseases poses a major challenge to coordinate sectorial control efforts within each industry [11]. Such juices have been found to be potential sources of bacterial pathogens, notably Escherichia coli, Salmonella spp., Shigella, and Staphylococcus aureus [12].

Currently, the other major concern to human health is the issue of antimicrobial resistance due to use of antibiotics in livestock production as well as human diseases conditions in developing countries. In Ethiopia, the major antibiotics used for treatment of animal and human diseases include penicillin, streptomycin, gentamycin, and oxytetracycline. Even though it needs a better understanding of antibiotics use in Ethiopia, this resistance variation might be due to indiscriminate use of antimicrobials in animal production without prescription in the animal and human health sector, which might favor selection pressure that increased the advantage of maintaining resistance genes in bacteria [13]. So far, there are no studies conducted on the burden and drug sensitivity profile of $E$. coli in Mekelle city, Northern Ethiopia. In this study, we isolated E. coli and determined the drug resistance profile.

\section{Materials and Methods}

2.1. Study Area. The study was conducted from October 2016 to June 2017 in Mekelle city. Mekelle is the capital city of Tigray Regional State located about $783 \mathrm{~km}$ north of Addis Ababa, the capital city of Ethiopia, at geographical coordination of $39^{\circ} 28^{\prime}$ east longitude and $13^{\circ} 32^{\prime}$ north latitude. The average altitude of the city is 2300 m.a.s.l. with a mean annual rainfall and average annual temperature of $629 \mathrm{~mm}$ and $22^{\circ} \mathrm{C}$, respectively [15]. The population of the city is 406,338 (195,605 males and 210,733 females) [15]. The city has seven subcities and 33 Kebeles where over 139 juice houses, 48 dairy farms, and 123 milk shops (street vendor or retailer shops) are inhabited. Besides, the cities possess an extensive public transport network and active urban-rural exchange of goods with about 30,000 micro and small enterprises.

2.2. Study Design. A cross-sectional survey was conducted from October 2016 to June 2017 on raw cow milk and fresh fruit juice samples collected from different sources of raw milk shops, dairy milk supply centers, and juice houses in Mekelle. Purposive sampling technique was employed.

\subsection{Research Methodology}

Sampling Technique and Collection. There were a total of 258 food samples among which 172 were milk samples (86 from milk shops and 86 from dairy farms) and the remaining 86 are fresh juice samples (from 86 juice houses) in Mekelle city. After aseptic collection, samples were labeled and packed with sterile bottles and transported with an ice box to Microbiology and Public Health Laboratories, College of Veterinary Medicine, Mekelle University, for bacterial isolation. Samples were processed immediately for bacterial identification to species level using culture media and then isolates were kept in refrigerator at $4^{\circ} \mathrm{C}$ until microbial characterization with regular subculturing [16].

Enumeration of Total Viable Count. $1 \mathrm{ml}$ and gram of raw milk and fruit juice samples, respectively, were homogenized into $9 \mathrm{ml}$ of serial peptone water/NSS and $10 \mathrm{~g} / 1 \mathrm{~g}$ of each food item was weighed out and homogenized into $90 \mathrm{ml} / 9 \mathrm{ml}$ of sterile distilled deionized water. Then serial dilutions were prepared. From the 10 -fold dilutions of the homogenates, $1 \mathrm{ml}$ of $10^{-6}, 10^{-7}$ and $10^{-8}$ dilutions was cultured in replicate on standard plate count agar (HiMedia, India), using the pour plate method. The plates were then incubated at $37^{\circ} \mathrm{C}$ for 24 to $48 \mathrm{hrs}$. At the end of the incubation period, colonies were counted using the illuminated colony counter. The counts for each plate were expressed as colony-forming unit of the suspension (CFU/g) [17].

Isolation and Characterization of Organism. $1 \mathrm{ml}$ and gram of thoroughly mixed raw milk and fruit juice sample, respectively, were aseptically added to $9 \mathrm{ml}$ of sterile nutrient broth and incubated overnight at $37^{\circ} \mathrm{C}$ for 24 hours. The mixture of nutrient broth and raw milk and fruit juice sample was subcultured on sterile nutrient agar plate under aseptic condition and incubated at $37^{\circ} \mathrm{C}$ for $18-24$ hours. Gram staining methods and further biochemical tests, catalase, carbohydrate utilization, indole production, citrate utilization, and methyl red tests, were carried out to identify the organisms that were isolated from the samples according to standard procedure described by $[17,18]$.

Antimicrobial Susceptibility Test. Antimicrobial susceptibility test, through Kirby diffusion test, was performed for all $E$. coli isolates following the protocol in [19]. At least 4-5 wellisolated colonies of the same morphological type are selected from a nonselective agar plate (nutrient agar); just the top of the colonies is touched and the growth transferred to a tube containing 4-5 $\mathrm{ml}$ of NSS or an equivalent medium such as peptone water broth. The inoculated broth is incubated at $35-37^{\circ} \mathrm{C}$ until a slight visible turbidity appears, usually within $2-8$ hrs. The turbidity of the preincubated broth and the suspension of bacteria are adjusted by comparison with $0.5 \mathrm{McF}$ arland turbidity standards. The standard and the test suspension are placed in similar $4-6 \mathrm{ml}$ thin glass tubes or vials. The turbidity of the test suspension is adjusted with broth or saline and compared with turbidity standard against a white background with contrasting black lines, until the turbidity of the test suspension equals the turbidity standard [19].

The bacterial suspension was inoculated on to MuellerHinton agar (Oxoid, UK) with the sterile swab to cover the whole surface of the agar. The inoculated plates were left at room temperature to dry. Before using the antimicrobial disks, they were kept at room temperature for one hour and then dispended on the surface of media. Following this, 
TABLE 1: Drug sensitivity interpretive zone of inhibition diameters.

\begin{tabular}{|c|c|c|c|c|c|}
\hline \multirow{2}{*}{ Antibiotics } & \multirow{2}{*}{ Disc code } & \multirow{2}{*}{ Potency } & \multicolumn{3}{|c|}{ Zone of diameter } \\
\hline & & & $S$ & $M$ & $R$ \\
\hline Erythromycin & ERY & $15 \mu \mathrm{g}$ & $\geq 23$ & $14-22$ & $\leq 13$ \\
\hline Cephalothin & $\mathrm{CF}$ & $30 \mu \mathrm{g}$ & $\geq 18$ & $15-17$ & $\leq 14$ \\
\hline Norfloxacin & $\mathrm{f}$ & $50 \mu \mathrm{g}$ & $\geq 17$ & $13-16$ & $\leq 12$ \\
\hline Sulfamethoxazole-trimethoprim & SXT-TMP & $300 \mu \mathrm{g}$ & $\geq 16$ & $11-15$ & $\leq 10$ \\
\hline Streptomycin & S & $10 \mu \mathrm{g}$ & $\geq 15$ & $12-14$ & $\leq 11$ \\
\hline Kanamycin & KAN & $30 \mu \mathrm{g}$ & $\geq 18$ & $14-17$ & $\leq 13$ \\
\hline Chloramphenicol & $\mathrm{CHL}$ & $30 \mu \mathrm{g}$ & $\geq 18$ & & $\leq 18$ \\
\hline Tetracycline & $\mathrm{TE}$ & $30 \mu \mathrm{g}$ & $\geq 22$ & $19-21$ & $\leq 19$ \\
\hline Gentamicin & GM & $10 \mu \mathrm{g}$ & $\geq 18$ & - & $\leq 18$ \\
\hline Ampicillin & AMP & $10 \mu \mathrm{g}$ & $\geq 15$ & $12-14$ & $\leq 11$ \\
\hline Ciprofloxacin & CIP & $5 \mu \mathrm{g}$ & $\geq 20$ & & $\leq 20$ \\
\hline Ceftriaxone & $\mathrm{CRO}$ & $30 \mu \mathrm{g}$ & $\geq 23$ & $20-22$ & $\leq 19$ \\
\hline Clindamycin & $\mathrm{CC}$ & $10 \mu \mathrm{g}$ & $\geq 21$ & $15-20$ & $\leq 14$ \\
\hline
\end{tabular}

Source: [14]. R: resistant; I: intermediate; S: sensitive.

TABLE 2: Total mean viable bacterial count for different sample types.

\begin{tabular}{lcccc}
\hline Sample type & Mean bacterial count & \pm SD & Minimum bacterial count & Maximum bacterial count \\
\hline Milk shop & $8.86 \pm 10^{7}$ & $33.87 \pm 10^{6}$ & $1.5 \pm 10^{7}$ & $1.25 \pm 10^{8}$ \\
Fruit juice & $7.2 \pm 10^{7}$ & $6.68 \pm 10^{6}$ & $6.37 \pm 10^{7}$ & $8.5 \pm 10^{7}$ \\
Dairy milk & $8.65 \pm 10^{7}$ & $22.0 \pm 10^{6}$ & $6.4 \pm 10^{7}$ & $1.23 \pm 10^{8}$ \\
\hline Total & $8.24 \pm 10^{7}$ & $23.8 \pm 10^{6}$ & $1.5 \pm 10^{7}$ & $1.25 \pm 10^{8}$ \\
\hline
\end{tabular}

SD: standard deviation.

the plates were incubated aerobically at $37^{\circ} \mathrm{C}$ for $24 \mathrm{hrs}$. The diameters of the zone of inhibition around the disks were measured to the nearest millimeter using calibrated rulers, and the isolates were classified as susceptible, intermediate, and resistant according to the interpretative accordance with the guidelines [20] (Table 1).

2.4. Data Management and Analysis. All data were checked against the standards and methods used to perform the study. Data was entered in Microsoft Excel spreadsheet and analyzed using STATA version 12. Descriptive statistics such as means, percentage, and frequencies were computed to report desired outputs. The antimicrobial resistance test was analyzed using WHONET software version 5 statistical package (http://www .who.int/medicines/areas/rational_use/AMR_WHONET_ SOFTWARE/en/). Analysis of variance (ANOVA) was used to test the significant difference at $P<0.05$.

\section{Results}

3.1. Total Viable Bacterial Count. The overall mean viable bacterial count recorded was $8.24 \pm 10^{7}$. The individual sample type mean viable count and standard deviation of milk shop, fruit juice, and dairy milk are found in Table 2.

3.2. Isolation and Identification of E. coli. Among the total 258 raw cow milk and fruit juice samples collected from different sources of Mekelle subcities, 115 (44.57\%) samples were found to be positive for E. coli. Proportions of the isolation from

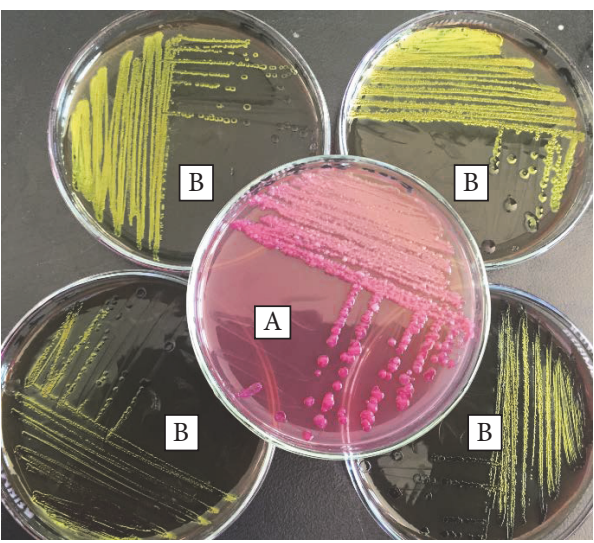

FIgURE 1: Colony observation on the two media. (A) MacConkey agar: smooth, circular pink colonies with spreading growth. (B) Eosin-methylene-blue agar: metallic sheen colony to growth.

milk shop, fruit juice, and dairy milk samples were indicated in Table 3. A statistically significant difference $\left(\chi^{2}=20.4580\right.$; $P$ value $=0.000)$ was recorded among samples from the three sites (Table 3 and Figure 1).

3.3. Antimicrobial Susceptibility Profile of E. coli. The antimicrobial resistance profiles of the bacterial isolates from raw cow milk and fruit juice samples were summarized in Table 4. E. coli showed resistance to antibiotics like ampicillin 
TABLE 3: E. coli from raw cow milk and fruit juice samples.

\begin{tabular}{|c|c|c|c|}
\hline Sample type & Number of positive (\%) & $\chi^{2}$ & $P$ value \\
\hline Milk shop $(n=86)$ & $55(63.95)$ & & \\
\hline Fruit juice $(n=86)$ & $27(31.40)$ & 20.4580 & 0.000 \\
\hline Dairy milk $(n=86)$ & $33(38.37)$ & & \\
\hline Overall $(n=258)$ & $115(44.57)$ & & \\
\hline
\end{tabular}

TABLE 4: Antimicrobial resistance of E. coli isolated from raw milk and fruit juice sample.

\begin{tabular}{lcccc}
\hline Antibiotic & \% resistant & \% intermediate & \% susceptibility & \% resistance at 95\% CI \\
\hline Ampicillin & 70 & 0 & 30 & 30 \\
Cefoxitin & 40 & 30 & 100 & $13.7-72.6$ \\
Gentamicin & 0 & 0 & 40 & $0.0-34.5$ \\
Kanamycin & 50 & 10 & 30 & $20.1-79.9$ \\
Streptomycin & 40 & 30 & 90 & $13.7-72.6$ \\
Ciprofloxacin & 0 & 10 & 100 & $0.0-34.5$ \\
Norfloxacin & 0 & 0 & 20 & $0.0-34.5$ \\
Sulfamethoxazole & 60 & 20 & 10 & $27.4-86.3$ \\
Clindamycin & 80 & 10 & 90 & $44.2-96.5$ \\
Polymyxin B & 10 & 0 & 30 & $0.5-45.9$ \\
Erythromycin & 60 & 10 & 40 & $27.4-86.3$ \\
Chloramphenicol & 50 & 10 & 60 & $20.1-79.9$ \\
Tetracycline & 20 & 20 & $3.5-55.8$ \\
\hline
\end{tabular}

TABLE 5: Multidrug resistance of E. coli isolated from raw cow milk and fruit Juices sample.

\begin{tabular}{llr}
\hline Antimicrobial resistance & Antimicrobial & Isolates (\%) \\
\hline & AMP (1) & $(100 \%, 1 / 1)$ \\
One & STR (1) & $(100 \%, 1 / 1)$ \\
& AMP, STR, ERY (1) & $(33 \%, 1 / 3)$ \\
Two & CHL, CIP, TCY, ERY (1) & $(25 \%, 1 / 4)$ \\
\hline Five & CHL, AMP, STR, ERY (2) & $(25 \%, 2 / 8)$ \\
\hline
\end{tabular}

AMP: ampicillin; ERY: erythromycin; CHL: chloramphenicol; CIP: ciprofloxacin; STR: streptomycin; TCY: tetracycline.

(70\%), sulfamethoxazole-trimethoprim $(60 \%)$, clindamycin (80\%), erythromycin $(60 \%)$, chloramphenicol $(50 \%)$, and kanamycin (50\%). The isolates were susceptible to some antibiotics like gentamicin (100\%), norfloxacin (100\%), tetracycline $(60 \%)$, polymyxin B (90\%), and ciprofloxacin $(90 \%)$.

The multidrug resistance profile of the bacterial E. coli isolates is presented and the mean antibiotic sensitivity of $E$. coli species from raw milk shop, fruit juice, and dairy milk samples was found to be $16.16,21.44$, and 28.24 , respectively (Table 5). In general, antimicrobial susceptibility test revealed that gentamicin, norfloxacin, polymyxin $\mathrm{B}$, and ciprofloxacin were the antimicrobials indicated as active against E. coli isolated from this study.

A total of 13 multiple drug resistance patterns were observed. The highest MDR noted was AMP and STR (100\%, $1 / 1)$. The maximum multiple drug resistance registered was resistance to one and three antibiotics with the combination AMP and STR, AMP STR ERY (Table 6).

\section{Discussion}

The current finding indicated that samples from milk shop, fruit juice, and dairy milk were found with a viable bacterial count load of $8.86 \pm 10^{7}, 7.2 \pm 10^{7}$, and $8.65 \pm 10^{7}, \mathrm{CFU} / \mathrm{ml}$, respectively, with an overall mean viable bacterial count of $8.24 \pm 10^{7} \mathrm{CFU} / \mathrm{ml}$. The highest mean value of microbial load $\left(8.86 \pm 10^{7} \mathrm{CFU} / \mathrm{ml}\right)$ was found from milk shop samples.

The current study showed a higher viable bacterial count than previous reports such as viable bacterial count from fresh fruit juice samples in Ethiopia [21] to raw milks for which a count was available, $96.8 \% \pm 10^{2} \mathrm{CFU} / \mathrm{ml}$, and raw milk cheeses for which a count was available, $98.6 \% \pm$ $10^{4} \mathrm{CFU/g}$ [22].

This variation could be due to hygiene difference, personal awareness, and proper handling of containers and the food itself. Furthermore, viable bacterial counts of 3.93 $\pm 0.01 \mathrm{CFU} / \mathrm{ml}$ [23] in milk samples from dairy farms in 
TABLE 6: In vitro antimicrobial sensitivity of $E$. coli isolated from different samples.

\begin{tabular}{lccccc}
\hline Sample type & Obs. & Mean & \pm SD & Min. & Max. \\
\hline Milk shop & 25 & 16.16 & 3.10 & 2.81 & 11 \\
Fruit juice & 25 & 21.44 & 3.95 & 22 & 26 \\
Dairy milk & 25 & 28.24 & 42 \\
\hline
\end{tabular}

SD: standard deviation; Obs.: observation.

Khartoum State (Sudan) and $3.64 \pm 0.776 \mathrm{CFU} / \mathrm{ml} 5[24]$ from raw milk samples were reported in Ethiopia.

In the present study, 115 out of 258 (44.57\%) samples were found to be positive for E.coli, of which 55 (63.95\%) were from milk shop, 27 (31.40\%) from fruit juice, and 33 (38.37\%) from dairy farms. The result showed a high contamination rate, which might be attributed to poor hygienic sanitation. Statistically significant difference $(P<0.05)$ among the sample types in the prevalence of E. coli was recorded. A similar report was also made by previous researchers in Ethiopia. Other researchers reported higher E. coli isolates in raw milk value chain from farmers $(89.74 \%)$ and shops (90.0\%) in Arusha, Tanzania [25].

The isolation rate of $E$. coli in the present study was found to be lower (44.57\%) compared to other reports such as those in Tanga, Tanzania, 100\% [26], in Arusha, Tanzania, 90.67\% [25], in Dar es Salaam, Tanzania, 83\% [27], raw milk along chain, in Tando Jam, Pakistan, 51.66\% [28] from milk vending shops, and 58\% [29] from raw cow's milk in Ethiopia, whereas it was higher compared to other reports in Ethiopia, 26.6\% [30], from milk sample from cafeteria.

The variation could be due to the reason that even when drawn under aseptic condition, milk always contains microorganisms that are derived from the milk ducts in the udder. In addition, contaminants coming from milking utensils, human handlers, unclean environmental conditions, and poor udder preparation might expose raw milk to bacterial contamination.

Antimicrobial resistance emerges from the use of antimicrobials in animals and human and the subsequent transfer of resistance genes and bacteria among animals, humans, animal products, and the environment. In Ethiopia, there have been reports on the drug resistance of $E$. coli isolates from animal-derived food products [31, 32]. The highest drug resistance recorded in the current study might be due to high antimicrobial use in dairy farms, fruit juices, and individual cows to treat various diseases affecting the dairy sector. Similarly, several studies have indicated that E. coli isolated showed high resistance to erythromycin (100\%), streptomycin (50\%), tetracycline (75\%), and ampicillin (50\%) and high sensitivity to penicillin (100\%), gentamicin (75\%), chloramphenicol (75\%), and amoxicillin (50\%) reported by [21] in Ethiopia.

Different researchers reported antimicrobial resistance of E. coli isolates of raw milk in their previous studies from Ethiopia. Reports from other researchers had also indicated E. coli isolates' resistance to ampicillin and cephalothin (84.6\%), chloramphenicol (83.3\%), tetracycline (88.9\%), and gentamicin (65.9\%) reported by [30] in Tigray, Ethiopia.

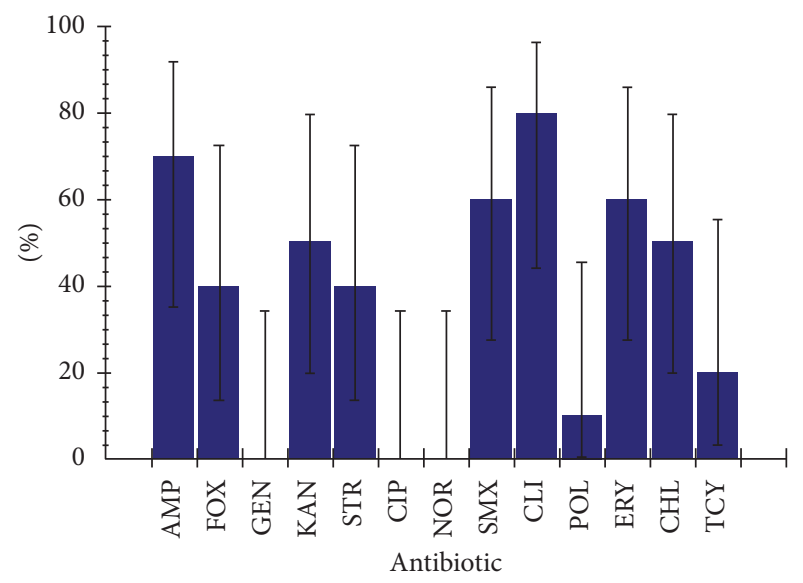

FIGURE 2: Antibiotic resistance profile of E. coli isolated from different samples.

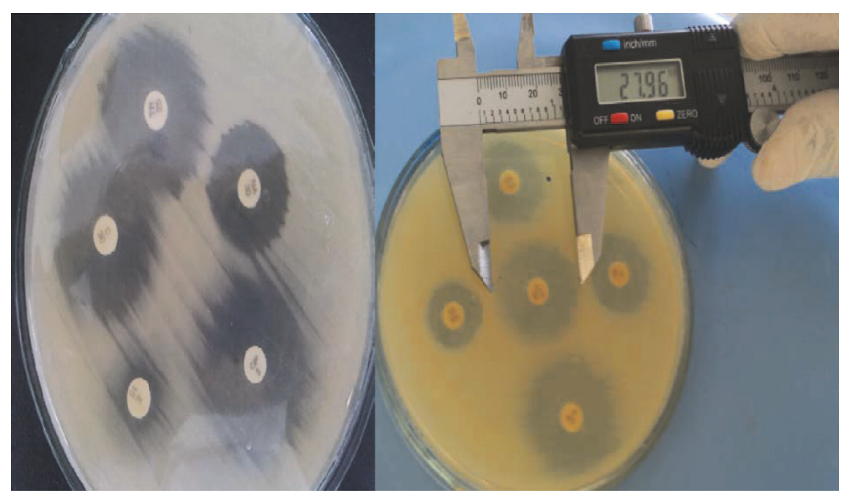

FIGURE 3: Antibiotic resistance profile and how to measure the inhibition zone of $E$. coli isolated from different samples.

Antibiotic resistance development among the bacteria poses a problem of concern. In all food samples in the present study, E. coli showed high resistance rates to ampicillin (70\%), sulfamethoxazole-trimethoprim (60\%), clindamycin (80\%), erythromycin $(60 \%)$, chloramphenicol $(50 \%)$, and kanamycin (50\%) and susceptibility to some antibiotics like gentamicin $(100 \%)$, norfloxacin $(100 \%)$, tetracycline $(60 \%)$, polymyxin B (90\%), and ciprofloxacin (90\%) (Figure 2). The results of this study are in line with the findings of other studies conducted in different parts of the world [33, 34]. However, antimicrobial resistance rates obtained in this study were higher as compared to susceptibility patterns reported from previous studies [35-37].

E. coli isolates were sensitive to gentamicin, norfloxacin, tetracycline, polymyxin B, and ciprofloxacin (Figure 3). 
Similar studies conducted in Ethiopia by [38] and in Nigeria by [39] have reported comparable susceptibility rates. In this study, gentamicin, norfloxacin, tetracycline, polymyxin $B$, and ciprofloxacin were found to be the most effective antimicrobials against E. coli isolates. Furthermore, in this study, a high rate of multiple antimicrobial resistance (100\%) was recorded, which is consistent with the reports of studies done elsewhere by other scholars $[40,41]$. Increases in rate of resistance to different antimicrobials have been reported from previous studies conducted in different parts of the world $[40,41]$. The remarkable degree of resistance to many drugs represents public health hazard due to the fact that foodborne outbreaks would be difficult to treat and this pool of MDR E. coli in food supply represents a reservoir for communicable resistant genes. Hence, due to the relatively limited access and high price to get the newly developed cephalosporin and quinolone drugs, the reports of prevalence of antimicrobialresistant $E$. coli to relatively low-priced and regularly available antibiotics are alarming for a low-income society living in most developing countries, like Ethiopia.

\section{Conclusion}

The current study gives insights into the magnitude and incidence of $E$. coli from raw cow milk and fresh fruit juice samples. The study revealed that the development of antibiotic resistance against $E$. coli could pose serious threat for consumers in the study area. Hence, attention should be given to proper handling of the food items and using recent antibiotics in the treatment of diseases both in humans and in animals.

\section{Abbreviations}

AMP: Ampicillin

ANOVA: Analysis of variance

CHL: Chloramphenicol

CIP: Ciprofloxacin

ERY: Erythromycin

I: Intermediate

MDR: Multiple drug resistance

NSS: Normal saline solution

R: $\quad$ Resistant

S: $\quad$ Sensitive

SD: $\quad$ Standard deviation

STR: Streptomycin

TCY: Tetracycline.

\section{Conflicts of Interest}

The authors declare that there are no conflicts of interest.

\section{References}

[1] WHO, "WHO's first ever global estimates of foodborne diseases," http://journals.plos.org/plosmedicine/article?id=10.1371/journal .pmed.1001923.

[2] S. P. Oliver, B. M. Jayarao, and R. A. Almeida, "Foodborne pathogens in milk and the dairy farm environment: food safety and public health implications," Foodborne Pathogens and Disease, vol. 2, no. 2, pp. 115-129, 2005.

[3] K. G. Torkar and S. G. Teger, "The microbiological quality of raw milk after introducing the two day's milk collecting system," Acta agriculturae Slovenica, vol. 92, no. 1, pp. 61-74, 2008.

[4] B. Srinu, A. V. Kumar, M. S. Kumar, B. V. L. Narayana, and T. M. Rao, "Assessment of microbiological quality and associated health risks of raw milk sold in and around Hyderabad city," International Journal of Pharma and Bio Sciences, vol. 3, no. 4, pp. 609-614, 2012.

[5] P. K. Virpari, J. B. Nayak, M. N. Brahmbhatt, and H. C. Thaker, "Study on isolation, molecular detection of virulence gene and antibiotic sensitivity pattern of Escherichia coli isolated from milk and milk products," Veterinary World, vol. 6, no. 8, pp. 541545, 2013.

[6] FSA (European Food Safety Authority) and ECDC (European Centre for Disease Prevention and Control), "The European union summary report on trends and sources of zoonoses, zoonotic agents and food-borne outbreaks in 2012," EFSA Journal, vol. 12, no. 2, article 3547, p. 312, 2012.

[7] R. Farzan, E. Rahimi, and H. Momtaz, "Virulence properties of Shiga Toxin-Producing Escherichia coli isolated from Iranian raw milk and dairy products," Slovenian Veterinary Research, vol. 49, no. 4, pp. 159-166, 2012.

[8] M. Rashid, S. K. Kotwal, M. A. Malik, and M. Singh, "Prevalence, genetic profile of virulence determinants and multidrug resistance of escherichia coli isolates from foods of animal origin," Veterinary World, vol. 6, no. 3, pp. 139-142, 2013.

[9] WHO, Regional office for Africa developing and maintaining food safety control systems for Africa current status and prospects for change, Second FAO/WHO Global Forum of Food Safety Regulators, Bangkok, Thailand, 2004.

[10] K. Molbak, E. O. John, and C. W. Henrik, "Salmonella infections," in Foodborne Infections and Intoxications, Elsevier, 2006.

[11] B. Molla, D. Alemayehu, and W. Salah, "Sources and distribution of Salmonella serotypes isolated from food animals, slaughterhouse personnel and retail meat products in Ethiopia: 1997-2002," Ethiopian Journal of Health Development, vol. 17, no. $1,2003$.

[12] B. Nicolas, B. Abdoul R., S. Aly, O. C. Amadou T., I. A. Jules, and T. Alfred S., "Hygienic status assessment of dish washing waters, utensils, hands and pieces of money from street food processing sites in Ouagadougou (Burkina Faso)," African Journal of Biotechnology, vol. 5, no. 11, pp. 1107-1112, 2006.

[13] H. Mekonnen, T. Habtamu, and A. Kelali, "Contamination of, raw , and, ready-to-eat, foods and their public health risks in Mekelle City, Ethiopia," ISABB Journal of Food and Agriculture Sciences, vol. 2, no. 2, pp. 20-29, 2012.

[14] CLSI, Performance Standards for Antimicrobial Disk and Dilution Susceptibility Tests for Bacteria Isolated from Animals, Clinical and Laboratory Standards Institute, 2008.

[15] TBA, Tigray Bearou of Administration Population Census Commission. Summary and Statistical Report of Population and Housing, Tigray bearou of Adiminstration, 2017.

[16] S. B. Oyeleke and S. B. Manga, Essentials of Laboratory Practical are in Microbiology, Tobest, Minna, Nigeria, 2008.

[17] M. O. Fawole and B. A. Oso, Laboratory Manual of Microbiology: Revised Edition, Spectrum Books Ltd, Ibadan, Nigeria, 2001.

[18] D. Roberts and M. Greenwood, Practical Food Microbiology, Blackwell Publishing Inc., USA, 3rd edition, 2003. 
[19] CLIS, Performance sTandards for Antimicrobial Susceptibility Testing; Twenty Second Informational Supplements, CLIS document M100-S22, Wayne, PA, USA, 2012.

[20] H. Jan, Kirby-Bauer Disk Diffusion Susceptibility Test Protocol, American society for microbiology, 2013, http://www .microbelibrary.org.

[21] G. Kindu, microbiological Safety of Fruit Juices Consumed in Cafes And Restaurants of Debre- Markos Town, North Western Ethiopia, Haramaya University, 2015.

[22] J. E. Coia, Y. Johnston, N. J. Steers, and M. F. Hanson, "A survey of the prevalence of Escherichia coli O157 in raw meats, raw cow's milk and raw-milk cheeses in south-east Scotland," International Journal of Food Microbiology, vol. 66, no. 1-2, pp. 63-69, 2001.

[23] A. A. Ali, "Incidence of Escherichia coli in raw cow's milk in Khartoum State," British Journal of Dairy Science, vol. 2, no. 1, pp. 23-26, 2011.

[24] T. Techlemichael, Quality and Safety of Raw and Pasteurized Cow Milk Produced and Marketed in Dire dawa Town Eastern Ethiopia, Haramaya University, 2012.

[25] L. Robert, S. Francis, and M. Athanasia, "Prevalence of Salmonella spp. and Escherichia coliin raw milk value chain in Arusha, Tanzania," American Journal of Research Communication, vol. 2, no. 9, pp. 1-13, 2014, http://www.usa-journals.com/.

[26] E. S. Swai and L. Schoonman, "Microbial quality and associated health risks of raw milk marketed in the Tanga region of Tanzania," Asian Pacific Journal of Tropical Biomedicine, vol. 1, no. 3, pp. 217-222, 2011.

[27] K. Kilango, K. Makita, L. Kurwijila, and D. Grace, "Food safety and the risk of exposure to milk borne pathogens in informal dairy markets in Tanzania," in Proceedings of the World Diary Summit Conference, Cape Town, South Africa, 2012.

[28] A. H. Soomro, M. A. Arain, M. Khaskheli, and B. Bhutto, "Isolation of escherichia coli from raw milk and milk products in relation to public health sold under market conditions at tandojam," Pakistan Journal of Nutrition, vol. 1, no. 3, pp. 151$152,2002$.

[29] M. A. Reta, T. W. Bereda, and A. N. Alemu, "Bacterial contaminations of raw cow's milk consumed at Jigjiga City of Somali Regional State, Eastern Ethiopia," International Journal of Food Contamination, vol. 3, no. 1, 2016.

[30] M. Abebe, A. Hailelule, B. Abrha et al., "Antibiogram of Escherichia coli strains isolated from food of bovine origin in selected Woredas of Tigray," Ethiopia, vol. 6, no. 3, pp. 17-22, 2014.

[31] O. Mohammed, D. Shimelis, P. Admasu, and T. Feyera, "Prevalence and antimicrobial susceptibility pattern of E. coli isolates from raw meat samples obtained from Abattoirs in Dire Dawa City, Eastern Ethiopia," International Journal of Microbiological Research, vol. 5, no. 1, pp. 35-39, 2014.

[32] M. Taye, T. Berhanu, Y. Berhanu, F. Tamiru, and D. Terefe, "Study on carcass contaminating Escherichia coli in apparently healthy slaughtered cattle in Haramaya University slaughter house with special emphasis on Escherichia coli o157:H7, Ethiopia," Journal of Veterinary Science \&Technology, vol. 4, no. 1, article no. 132, 2013.

[33] M. J. Bharathi, R. Ramakrishnan, V. Maneksha, C. Shivakumar, V. Nithya, and S. Mittal, "Comparative bacteriology of acute and chronic dacryocystitis," Eye, vol. 22, no. 7, pp. 953-960, 2008

[34] D. Briscoe, A. Rubowitz, and E. I. Assia, "Changing bacterial isolates and antibiotic sensitivities of purulent dacryocystitis," Orbit, vol. 24, no. 2, pp. 95-98, 2005.
[35] G. G. Zhanel, T. L. Hisanaga, N. M. Laing et al., "Antibiotic resistance in Escherichia coli outpatient urinary isolates: final results from the North American Urinary Tract Infection Collaborative Alliance (NAUTICA)," International Journal of Antimicrobial Agents, vol. 27, no. 6, pp. 468-475, 2006.

[36] J. A. Karlowsky, L. J. Kelly, C. Thornsberry, M. E. Jones, and D. F. Sahm, "Trends in antimicrobial resistance among urinary tract infection isolates of Escherichia coli from female outpatients in the United States," Antimicrobial Agents and Chemotherapy, vol. 46, no. 8, pp. 2540-2545, 2002.

[37] S. P. Barrett, M. A. Savage, M. P. Rebec, A. Guyot, N. Andrews, and S. B. Shrimpton, "Antibiotic sensitivity of bacteria associated with community-acquired urinary tract infection in Britain," Journal of Antimicrobial Chemotherapy, vol. 44, no. 3, pp. 359-365, 1999.

[38] G. Tesfaye, D. Asrat, Y. Woldeamanuel, and M. Gizaw, "Microbiology of discharging ears in Ethiopia," Asian Pacific Journal of Tropical Medicine, vol. 2, no. 1, pp. 60-67, 2009.

[39] B. A. Wariso and S. N. Ibe, "Bacteriology of chronic discharging ears in Port Harcourt, Nigeria," West African Journal of Medicine, vol. 25, no. 3, pp. 219-222, 2006.

[40] F. A. Orrett and S. M. Shurl, "Prevalence of resistance to antimicrobial of E. coli isolates from clinical sources at a private hospital in Trinidad," Japanese Journal of Infectious Diseases, vol. 54, pp. 64-68, 2001.

[41] S. Kurutepe, S. Surucuoglu, C. Sezgin, H. Gazi, M. Gulay, and B. Ozbakkaloglu, "Increasing antimicrobial resistance in Escherichia coli isolates from community-acquired urinary tract infections during 1998-2003 in Manisa, Turkey," Japanese Journal of Infectious Diseases, vol. 58, no. 3, pp. 159-161, 2005. 

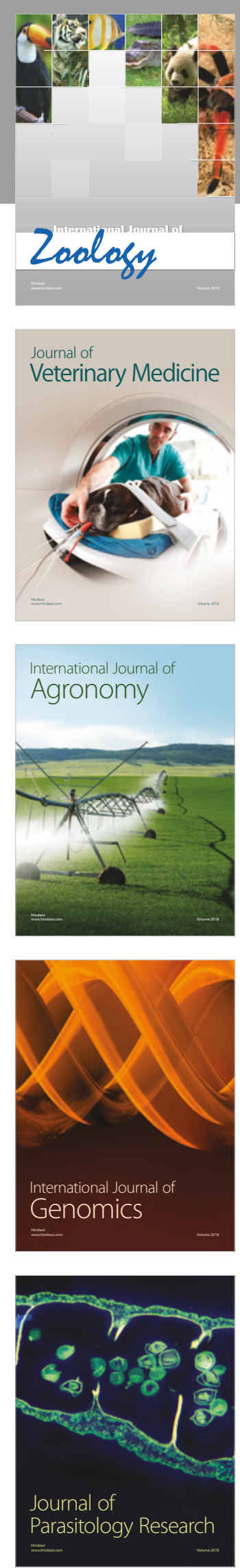

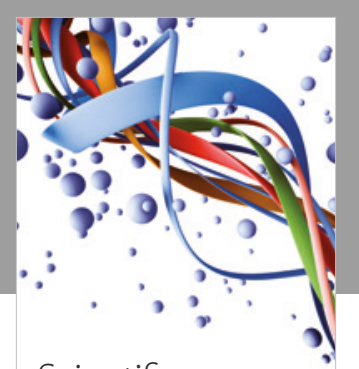

Case Reports in Veterinary Medicine Scientifica
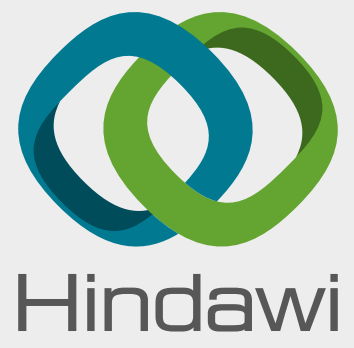

Submit your manuscripts at

www.hindawi.com
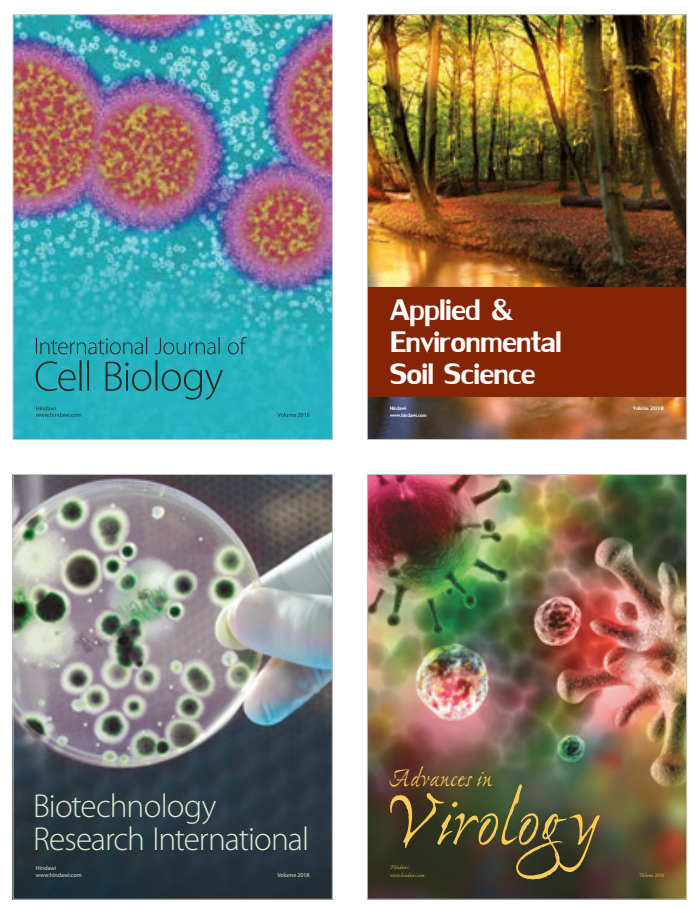

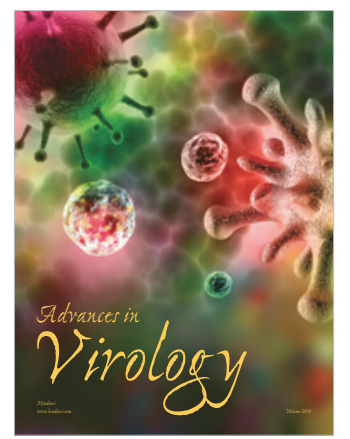

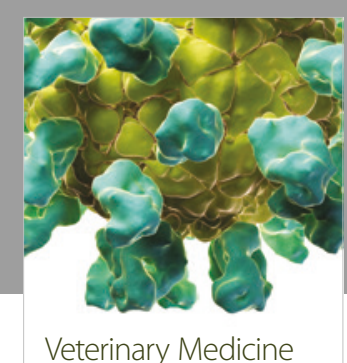
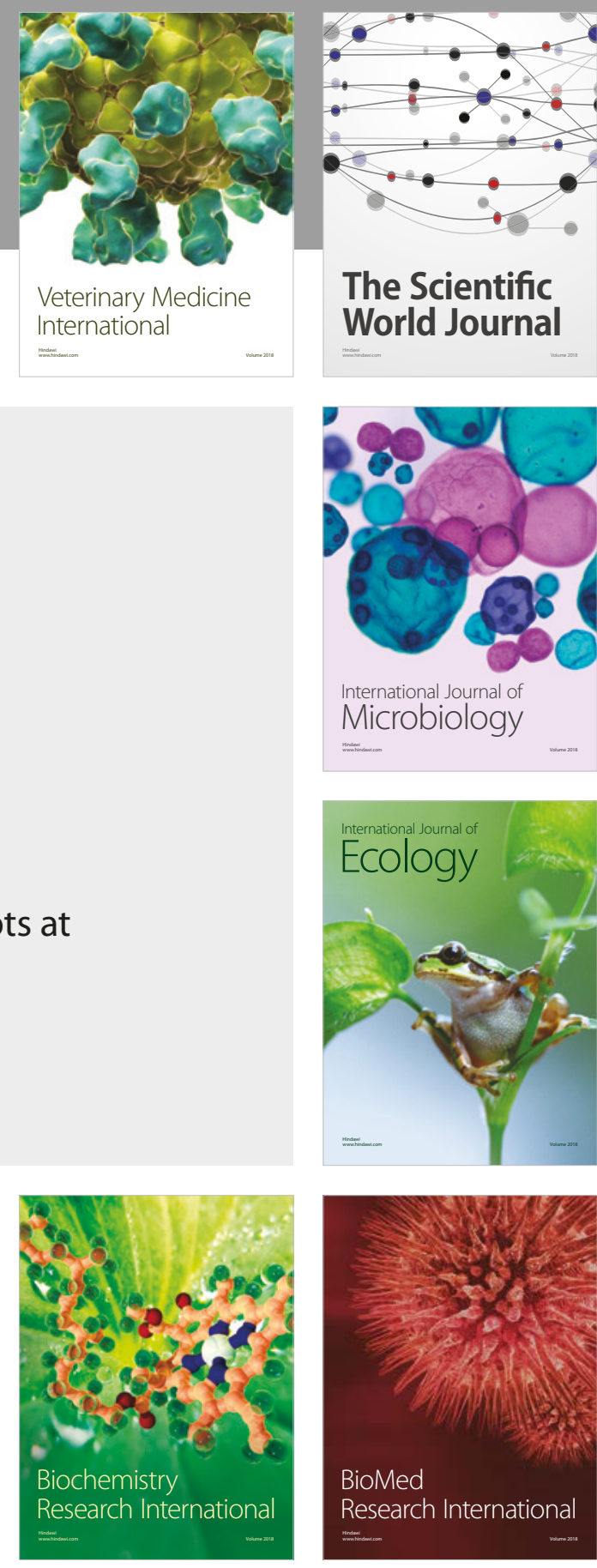

The Scientific World Journal

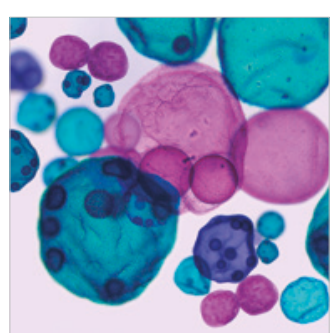

International Journal of Microbiology
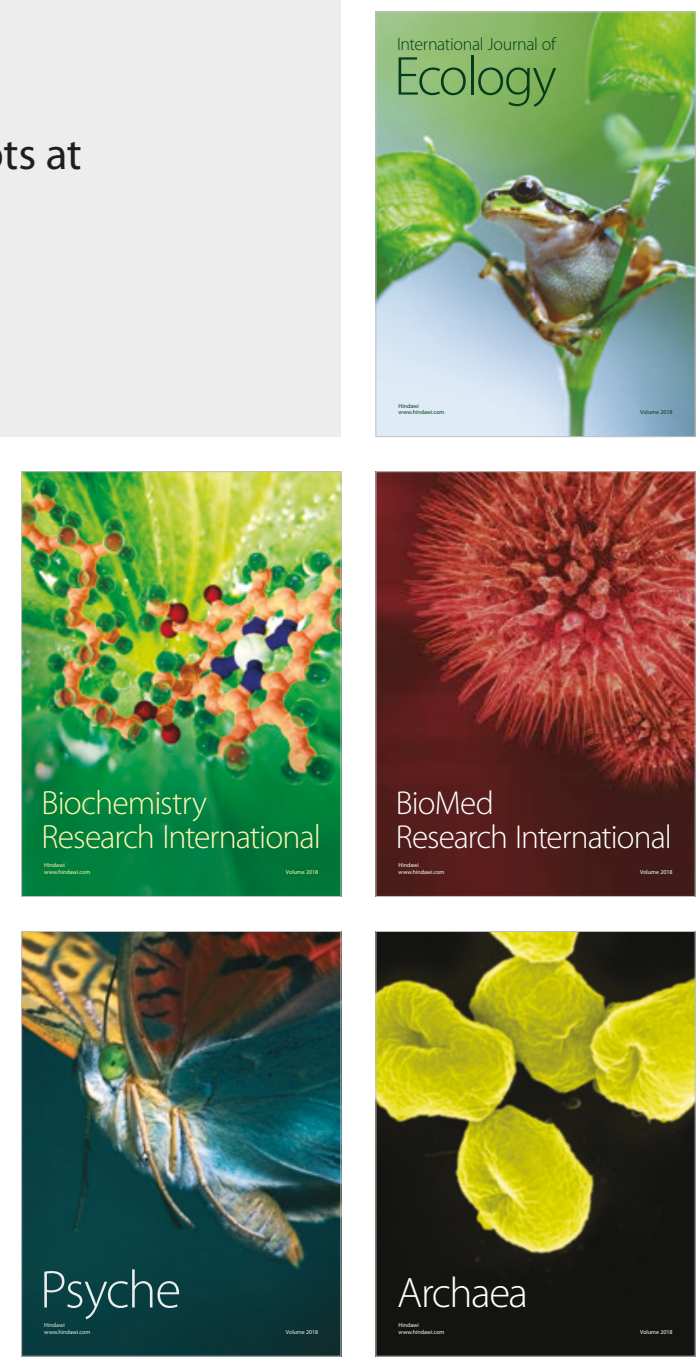